\title{
Occurrence of fault zone materials obtained from Nojima fault by Jet Form Boring(JFB)
}

\author{
川端訓代 * 塚田基治 ** 田中秀実 \\ Kuniyo Kawabata ${ }^{*}$ Motoharu Tsukada ${ }^{* *}$ and Hidemi Tanaka*
}

Recived January 5, 2005. Accepted April 5, 2005. C Coressponding author: K. Kawabata, kuniyo@eps.s.u-tokyo.ac.jp

* 東京大学大学院理学系研究科地球惑星科学専攻. Department of Earth and Planetary Science, University of Tokyo, 7-3-1, Hongo, Bunkyo-ku, Tokyo 113-0033, Japan

**＼cjkstart株式会社エルデ・ジャパン. Erde Japan Co., Ltd. 6-28-3 Kamariyanishi, Kanazawa-ku, Yokohama, Kanagawa 236-0046, Japan

On October 2003, short drilling ( $<10 \mathrm{~m}$ in length) was carried out at Nojima-Hirabayashi along the Nojima fault, Awaji Island, SW Japan. It has been difficult to recover perfect succession of fault zone materials by conventional drilling so far, since they are generally composed of a mixture of weak and hard materials and weak materials are dissolved and flown out with mud water. Therefore we tried a new technique called "Jet Form Boring (JFB)" in order to recover perfectly fault zone materials. JFB technique has been applied to unconsolidated deposits in landslide area and obtained porous and fragile materials completely. We chose three locations for JFB drilling along surface ruptures generated by 1995 Hyogo-ken Nambu earthquake where maximum displacement was identified by Trench study (Otsuki et al., 2003) (Fig. 1). We penetrated through the fault zones at two boreholes (Fig. 1) , one is within granodiorite (Borehole 1, Fig. 3.b) and another contains boundary between granodiorite and sediments (Borehole 2, Fig. 3.a). As shown in the figures, almost perfect successions of cores were recovered. The occurrences of the cores suggest that this technique is efficient for recovering fault zone materials. In this pictorial we introduce Nojima fault zone cores including fault surfaces obtained by JFB drilling.

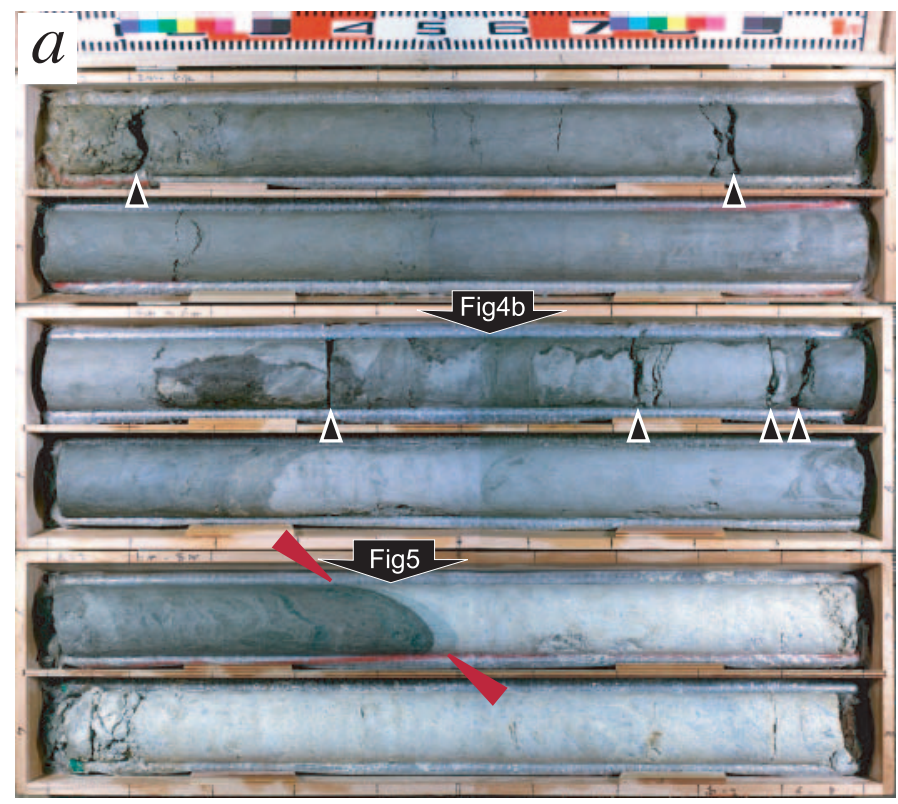

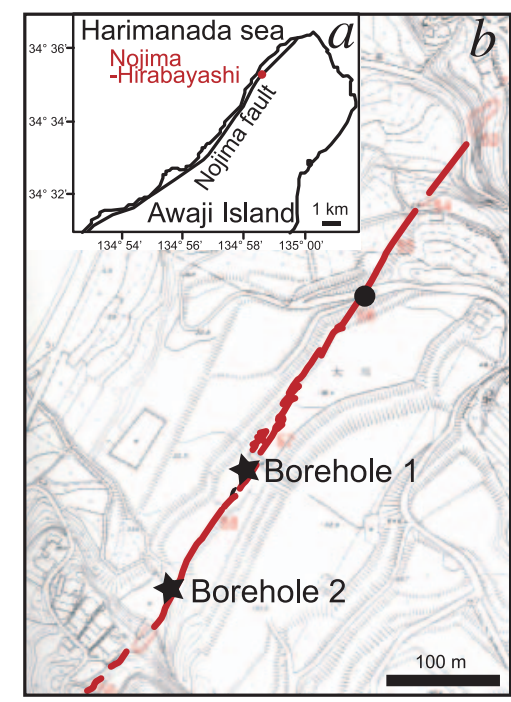

Fig. 1. (a) North district of Awaji Island. A filled circle indicates Nojima-Hirabayashi area. (b) Detailed distribution of surface ruptures indicated by red lines around NojimaHirabayashi area (Nakata and Okada, 1999) which were generated by 1995 earthquake. Filled stars and a filled circle indicate drilling sites and a trench site (Otsuki et al., 2003) respectively

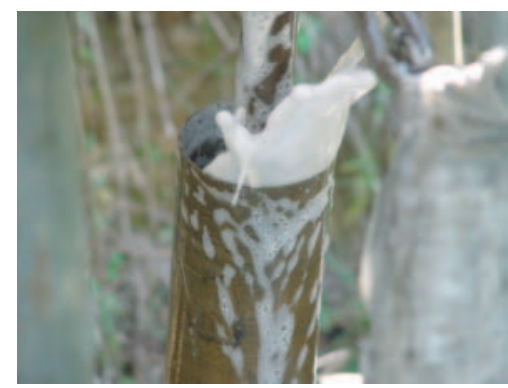

Fig. 2. Chemical bubbles are flown out from a boring hole. JFB technique employs specific chemical bubble developed by Erde Japan Co., Ltd. The chemical bubbles greatly assist to recover unconsolidated fault zone materials.

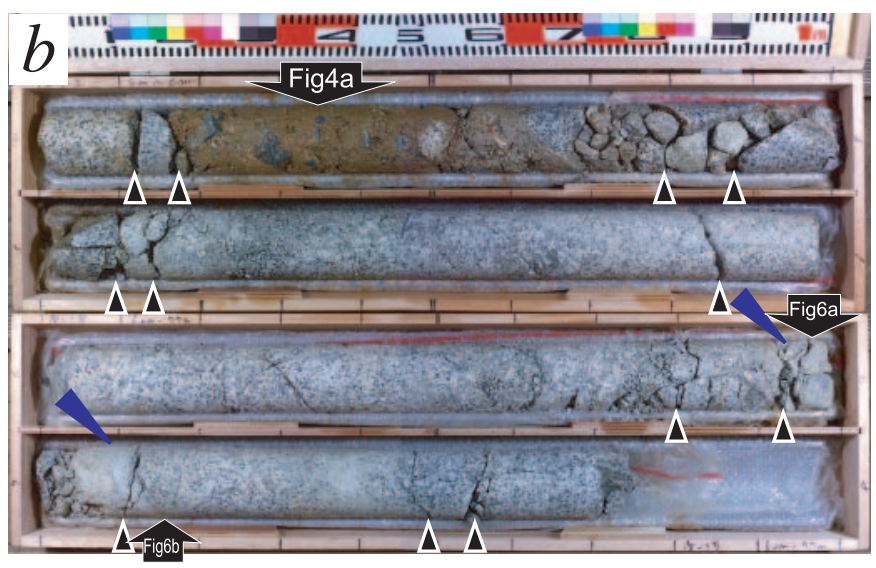

Fig. 3. Occurrence of drilled cores. Black arrows show artificial fractures. Fault zones were penetrated from west (footwall) to east (hanging wall). Depth increase from top to bottom and also from left to right. (a) Drilled cores (from 2.0 to $8.0 \mathrm{~m}$ depth) from the Borehole 2. Red arrows indicate the boundary between fault rocks originated from mudstone (left) and granodiorite (right). A dark brown colored and thin ultracataclasite layer is observed along the boundary. Polished surface of the core including the boundary is shown in Fig 5. Granodiorite in the hanging wall is intensely altered and fractured compared with sedimentary rocks in footwall. (b) Occurrence of drilled cores (from 4.0 to $7.7 \mathrm{~m}$ depth) from the Borehole 1. Blue arrows indicate the top and bottom boundaries of the fault zone. Enlargement figures of a fault zone and slip surface are shown in Fig 6.

\section{References}

Nakata, T. and Okada, A. eds, 1999, Nojima Fault: Pictorial Record and Explanatory Text ; Surface Fault Ruptures Associated with the 1995 HyogokenNambu Earthquake, 72, Univ. Tokyo Press.

Otsuki, K., Monzawa N. and Nagase, T., 2003, Fluidization and melting of fault gouge during seismic slip: Identification in the Nojima fault zone and implications for focal earthquake mechanisms. Jour. Geophys. Res, 108(B4), 2192, doi: 10. 1029/2001 JB001711. 


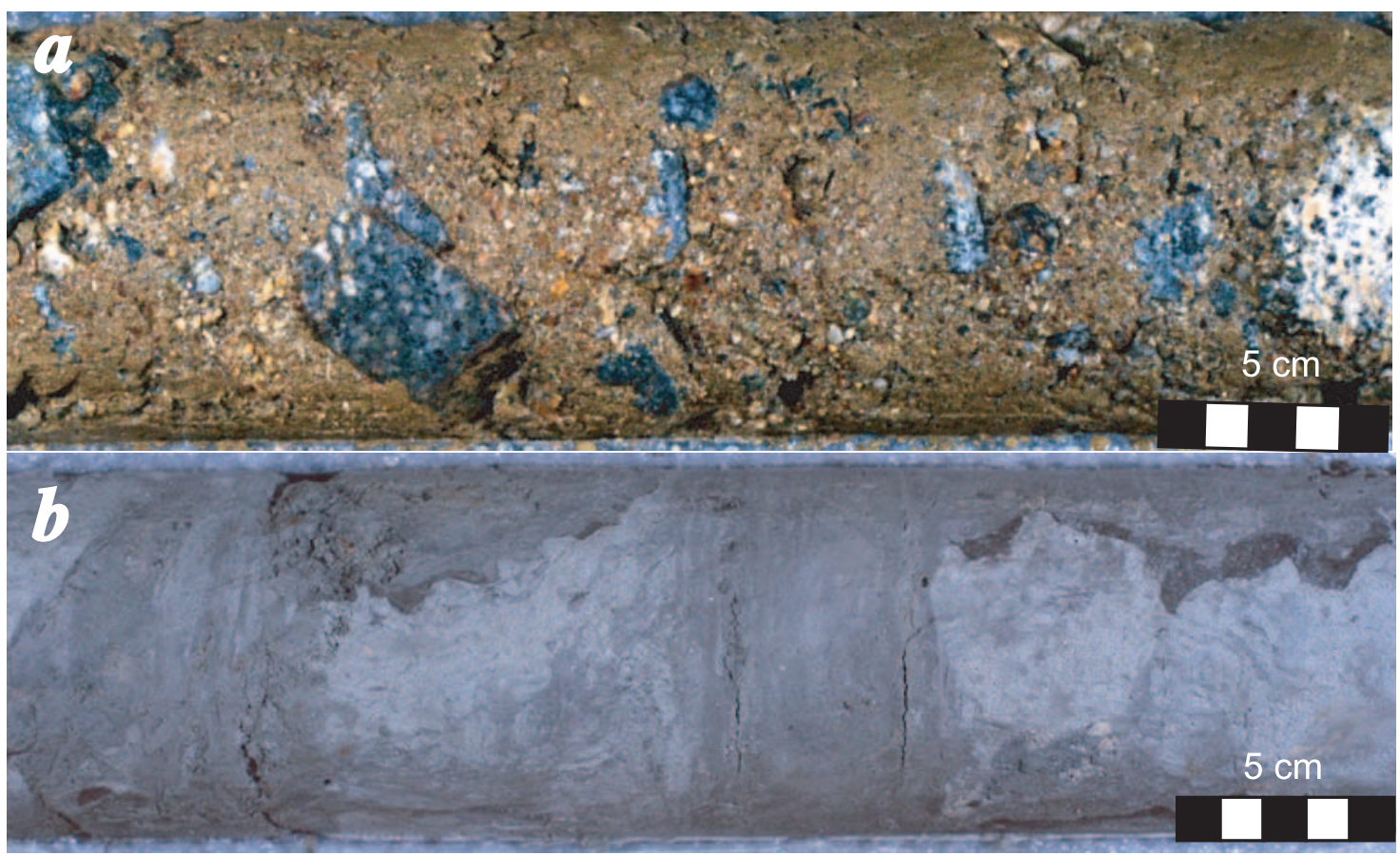

Fig. 4. (a) Occurrence of a part of drilled cores in the Borehole 1 (from 4.20 to $4.50 \mathrm{~m}$ depth). Recovery of the core is surprising, because it is composed of extremely porous and fragile talus deposits including hard granodiorite gravels. When these materials are penetrated by conventional drilling, matrix materials are readily crumbled by water circulation and vibration by bit rotation. (b) Occurrence of a part of cores in the Borehole 2 (from 4.40 to $4.70 \mathrm{~m}$ depth). The core is composed of unconsolidated mud and sand. The sand is in fault contact with mud. A dark brown colored layer is observed along the irregular boundary. Deformation structures are preserved in mud.

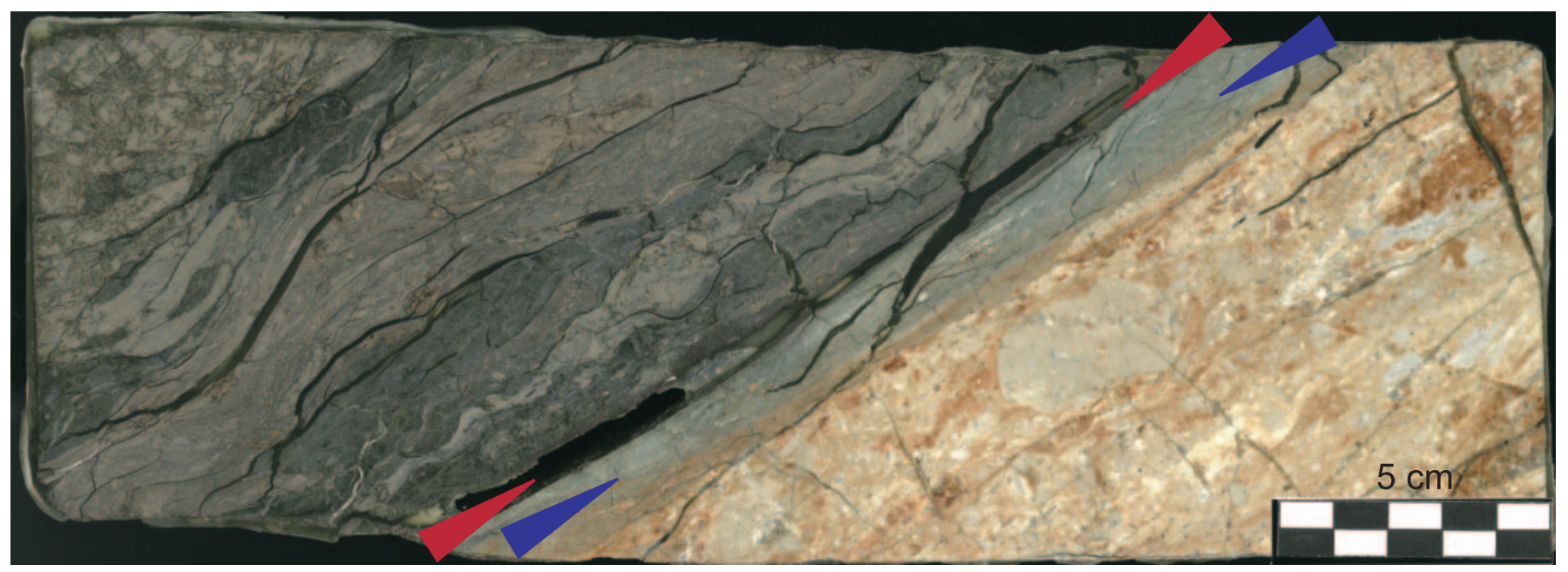

Fig. 5. Polished surface of a core of the fault zone recovered from the Borehole 2 (red arrows in Fig. 3). Sharp slip surface is clearly observed between fault rocks originated from mud (left) and those from granodiorite (right). Extremely thin, dark brown layer (approximately 2.0 to $3.0 \mathrm{~mm}$, red arrows) and grayish green colored ultracataclasite (approximately 20 to $30 \mathrm{~mm}$, blue arrows) are arranged parallel to the boundary. Flow textures are observed in the fault rocks originated from mud.

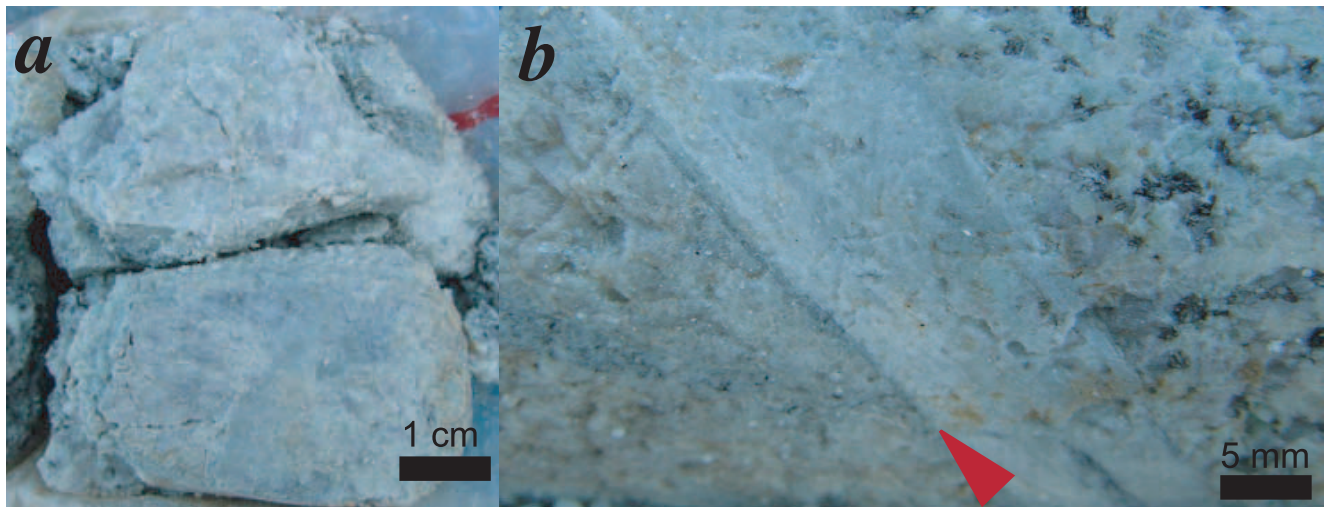

Fig. 6. Magnified view of fault zone cores in the granodiorite from the Borehole 1 (blue arrows in Fig.3). (a) Slicken lines are preserved on the slip surface. (b) The bottom slip surface of the fault zone. Red arrow shows the slip surface being boundary between fault rock (left) and host rock (right). Thin grayish colored layer and mineral veins are observed along the boundary. 